\title{
PROPOSED MODEL FOR OPTIMIZATION OF CONSTRAINED MULTIPASS TURNING OPERTAION
}

\author{
Omar M. Elmabrouk', Osama M. Erfan ${ }^{2}$, and Saleh M. Amaitik ${ }^{1}$ \\ ${ }^{1,2}$ Department of Industrial Engineering and Manufacturing Systems, \\ Faculty of Engineering, University of Garyounis, Libya \\ ${ }^{2}$ On leave from University of Banyswef, Egypt \\ E-mail: 'ommabrouk@yahoo.com \\ 2osamabanyswef@yahoo.com, ${ }^{2}$ osama_ahmed@garyounis.edu
}

(Received March 15, 2009 Accepted June 25, 2009).

\begin{abstract}
There have been a number of ways of subdivision of total depth of cut during cost optimization in constrained multipass turning operation. The total production cost minimization is achieved by summation of the minimum costs of individual rough passes and finish pass based on the maximum possible selection of depth of cut for finish pass and distributing the balance of depth of cut among passes such as to achieve minimum range variation among all. The resulting subdivision of depth of cut yields lower or equal costs when compared to those determined by using traditional and nontraditional approaches suggested by other researchers.
\end{abstract}

KEYWORDS: rough turning, finish turning, depth of cut, optimization

\section{INTRODUCTION}

In metal cutting operation, it is vital interest to the manufacturing engineer to consider production costs and of production rates. Although, in practice a high production rate would probably mean low production costs, it should be pointed out that these two factors must be considered separately and that the manufacturing conditions giving maximum production rate will not be identical to those conditions giving minimum cost of production.

Analysis of production costs and production rates can be a complicated subject, and in many cases, the analysis will apply only to the particular operation in question. However, experience gained over the years had lead to certain empirical rules or guiding principles for choosing the optimum cutting conditions for a given machining operation, and it is the objective of this paper to illustrate how multipass turning operation can be optimized under certain constraints.

In this study, the optimization is gained by minimizing the production cost which can be defined as the total average cost of performing the machining operation on a component using one machine tool.

\section{PREVIOUS WORK}

Machining economics has long been a field of interest for many researches. In this regard, the setting of speed, feed and depth of cut for the purpose of minimizing cost is 
made. The maximum depth of cut for an individual pass is usually limited by either chatter or the physical dimension of a particular tool. Multipass turning is used if the amount of stock to be removed, as expressed by the total depth of cut, exceeds the maximum allowable depth of cut. As such, the subdivision of depth of cut is an important decision in multipass turning. Relatively little research work has been directed toward this type of problem.

\section{NOMENCLATURE}

\begin{tabular}{|c|c|}
\hline \multicolumn{2}{|c|}{$\mathrm{A}_{1}, \mathrm{~A}_{2}, \mathrm{~A}_{3}$ Constants } \\
\hline $\mathrm{C}_{\mathrm{ij}}$ & $\begin{array}{l}\text { Minimum cost corresponding to } \\
d_{i j} \text { depth of cut, } \$ / \text { piece }\end{array}$ \\
\hline $\mathrm{d}_{\mathrm{ij}}$ & $\begin{array}{l}\text { jth - Element of depth of cut } \\
\text { series for ith pass, mm }\end{array}$ \\
\hline $\mathrm{d}_{\mathrm{i} \min }$ & $\begin{array}{l}\text { Minimum allowable depth of cut } \\
\text { for ith pass, } \mathrm{mm}\end{array}$ \\
\hline $\mathrm{d}_{\mathrm{i} \max }$ & $\begin{array}{l}\text { Maximum allowable depth of cut } \\
\text { for ith pass, } \mathrm{mm}\end{array}$ \\
\hline$d_{r}$ & Depth of cut for rough pass, $\mathrm{mm}$ \\
\hline $\mathrm{d}_{\mathrm{s}}$ & Depth of cut for finish pass, $\mathrm{mm}$ \\
\hline$d_{t}$ & Total depth of cut, $\mathrm{mm}$ \\
\hline $\mathrm{D}$ & Work piece diameter, mm \\
\hline$f_{r}$ & Feed for rough pass, $\mathrm{mm} / \mathrm{rev}$ \\
\hline$f_{s}$ & Feed for finish pass, $\mathrm{mm} / \mathrm{rev}$ \\
\hline $\mathrm{f}_{\min }$ & $\begin{array}{l}\text { Minimum allowable feed, } \\
\mathrm{mm} / \mathrm{rev}\end{array}$ \\
\hline $\mathrm{f}_{\max }$ & $\begin{array}{l}\text { Maximum allowable feed, } \\
\mathrm{mm} / \mathrm{rev}\end{array}$ \\
\hline $\mathrm{h}_{1}, \mathrm{~h}$ & $\begin{array}{l}\text { Constants pertaining to tool } \\
\text { travel and approach/depart time }\end{array}$ \\
\hline $\mathrm{k}_{0}$ & Over feed cost, $\$ / \mathrm{min}$ \\
\hline $\mathrm{k}_{1}$ & $\begin{array}{l}\text { Constant in cutting force } \\
\text { equation }\end{array}$ \\
\hline $\mathrm{k}_{\mathrm{t}}$ & $\begin{array}{l}\text { Cost of a cutting edge, \$/cutting } \\
\text { edge }\end{array}$ \\
\hline & work piece length, $\mathrm{mm}$ \\
\hline
\end{tabular}

$\mathrm{A}_{1}, \mathrm{~A}_{2}, \mathrm{~A}_{3}$ Constants

$\mathrm{C}_{\mathrm{ij}} \quad$ Minimum cost corresponding to

$\mathrm{d}_{\mathrm{ij}} \quad \mathrm{jth}$ - Element of depth of cut

$d_{i \min }$ Minimum allowable depth of cut

Maximum allowable depth of cut for ith pass, $\mathrm{mm}$

$d_{r} \quad$ Depth of cut for rough pass, $\mathrm{mm}$

$d_{s} \quad$ Depth of cut for finish pass, $m m$

$\mathrm{d}_{\mathrm{t}} \quad$ Total depth of cut, $\mathrm{mm}$

$\mathrm{D}$ Work piece diameter, $\mathrm{mm}$

$\mathrm{f}_{\mathrm{r}} \quad$ Feed for rough pass, $\mathrm{mm} / \mathrm{rev}$

$\mathrm{f}_{\mathrm{s}} \quad$ Feed for finish pass, $\mathrm{mm} / \mathrm{rev}$

$\mathrm{f}_{\min }$ Minimum allowable feed,

$f_{\max }$ Maximum allowable feed,

Constants pertaining to tool

travel and approach/depart time

$\mathrm{k}_{0} \quad$ Over feed cost, \$/min

$\mathrm{k}_{1} \quad$ Constant in cutting force

$\mathrm{k}_{\mathrm{t}}$

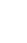

$m_{i} \quad$ Assumed number of divisions of depth of cut range in ith pass

$\mathrm{n} \quad$ Assumed maximum number of rough passes

$\mathrm{R}_{\mathrm{a}} \quad$ The range

Ts Tool life in finish pass, min.

U Total production cost per unit, $\$ /$ piece

$\mathrm{UCr}$ Total cost for rough pass, $\$ /$ piece

Vmin Minimum cutting speed, $\mathrm{m} / \mathrm{min}$

Vmax Maximum cutting speed, $\mathrm{m} / \mathrm{min}$

$\mathrm{Vr} \quad$ Cutting speed for rough pass, $\mathrm{m} / \mathrm{min}$

Vs Cutting speed for finish pass, $\mathrm{m} / \mathrm{min}$

$\mu, v \quad$ Exponents of feed and depth of cut in cutting power equation

$\eta \quad$ Constant

\section{Subscripts:}

i for ith rough pass

$\mathrm{j}$ for jth value of depth of cut

\section{Superscript:}

opt optional pass

* Corresponding to minimum value for single rough pass or finish pass

Iwata et al. [1] dealt with the problem of optimizing the number of passes required together with the cutting speed, the feed, and the depth of cut at each pass for a given total depth of cut to be removed from the work piece, considering both the probabilistic nature of the objective function and the constraints in the machining processes. Applying the concept of dynamic programming and stochastic programming to solve the single pass problem, it has been realized that, this is not a simple dynamic programming problem since the optimal number of passes (or number of stages in a multistage decision system) are not predetermined and they are to be determined during optimization. 
Lambert and Walvekar [2] have also developed a dynamic programming model for multipass turning operation under constraints of force, cutting power and surface finish, but they have, however, considered two pass turning examples only. Subsequently, Yellowbelly and Gunn [3] have shown that for both turning and milling operations, the optimal subdivision of depth of cut may be determined without knowledge of the relevant tool life equation, the important constraint of surface finish of the final product thus left out and they have considered cutting power and torque constraints. For practical considerations, this does not seem to be right since the quality of the final product depends on the surface finish achieved in the finish pass.

Shin and Joo [4] have presented a practical method of optimizing machining parameters under the minimum production cost criterion and realistic machining constraints. A mathematical model has been developed for this multi-variable, nonlinear programming problem. By dividing the cutting process to multi-pass rough cutting and finish cutting operation, the model has been proved to be more realistic. A practical strategy of planned tool replacement has been adopted and the machine idle time, which typically is considered to be constant, was redefined as sum of constant and variable terms. Further, several machining constraints have been considered including surface finish constraint. For optimization, the conventional differential method and dynamic programming method have been used, leading to a relatively simple and reliable optimal solution for the optimization problem. However, they have selected depths of cut based on using the minimum depth of cut in the finish pass and a number of rough passes of equal size such that the minimum cost is obtained. This practice does not yield an optimal solution when compared with the approach presented by Gupta et al [5]. In their work, the production cost model of Shin and Joo [4] was adopted and suitably modified to incorporate a method of determining the optimal subdivision of the total depth of material to be removed. The total production cost minimization was achieved in two steps. The first step was the minimization of costs for rough and finish passes for various fixed depths of cut. The values of depths of cut were selected from a series of allowable depths. In the second step, an optimal combination of depths of cut of rough passes and the finish pass, the optimal number of passes, and the minimum cost were determined. An integer programming model was developed for this purpose. The minimum total production cost, subdivision of total depth of cut and optimal number of rough passes were determined. Techniques such as integer programming, geometric programming, dynamic programming and 'branch and bound' techniques tend to obtain a local optimal solution. Considering the drawbacks of traditional optimization techniques, attempts are being made to optimize the machining problem using nontraditional techniques [6-11].

\section{SOLUTION PROCEDURE FOR THE SUGGESTED APPROACH}

Optimization of metal cutting operation means determination of the optimal set of operating conditions to satisfy an economic objective within the operations constraints. The results obtained from the optimization search will depend on the mathematical model of the process, and greater extent on the optimization method used. However, there is a large number of metal cutting optimization techniques which may be used for 
engineering applications. Each of these techniques has its features, merits and limitation. Hence, the successful use of a technique in one of the engineering applications does not mean that this technique is suitable for all other applications. The final decision of selection of one of the optimization methods depends upon the case being investigated, the individual preference and the individual experience. In the current study the optimization problem can be decomposed into two separate optimization subproblems for roughing and finishing operation which convey a similarity to the concept of dynamic programming.

\subsection{Concept of Dynamic Programming}

Dynamic programming is a well known technique of operations research. It is a mathematical procedure designed primarily to improve the computational efficiency of solving selected mathematical programming problems. Dynamic programming is basically concerned with the theory of multi-stage decision processes which may be of a deterministic nature when once a decision is made the outcome is uniquely determined. The two fundamental features of dynamic programming are: first, the original problem has been reduced to a series of subproblem stages each with exactly one optimizing variable and second, the decision making mechanism is such that once a decision is made for a particular stage, this must be followed by the best, or optimum decision for the rest of other stages. The computations at the different stages are linked together and the optimal solution to the entire problem is reached.

\subsection{The Model}

Based on the minimum cost criterion, the well - known objective function for multipass turning using the extended Taylor's tool life equation is given by [5]:

$$
U=U_{C_{S}}+\sum_{i=1}^{n} U_{C_{r i}}+A_{5}
$$

where

$$
A_{5}=k_{o} t_{p}
$$

The cost for a single finish pass is given by

$$
U_{C_{S}}=A_{2}+A_{1} f_{S}^{(q / p-1)} d_{S}^{r / p}
$$

Where

$$
\begin{aligned}
& A_{1}=\frac{\pi D L k_{0}}{100 \sigma_{p}}\left[\frac{T_{S}}{C_{o}}\right]^{1 / p}\left[T_{S}+\zeta\left(t_{e}+\frac{k_{t}}{k_{o}}\right)\right] \\
& A_{2}=k_{0}\left(h_{1} L+h_{2}\right)
\end{aligned}
$$

and the relationship between Tp and TS is defined as

$$
T_{p}=T_{S} / \zeta
$$

For minimization of production cost, there are several constraints to be considered, i.e. speed constraint, feed constraint, depth of cut constraint, surface finish constraint cutting force constraint and power constraint. 


\subsection{The Solution Methodology}

Minimum total production cost will be adapted as the objective criterion for the formulation of the problem. There are two phases by which the total production cost is achieved. In the first phase, separate minimum cost for the individual rough passes and finish pass are determined - and tabulated for various fixed values of depth of cut. The value of depth of cut is selected from a series of depths. In the second phase, optimal subdivisions of depth of cut for rough passes and finish pass, optimal number of passes and minimum total production cost are determined using a modified dynamic programming approach.

\section{Phase 1}

This phase consists of determining costs for individual finish or rough pass considering various fixed values of depth of cut. A series of depths of cut is defined. The jth element of the series, for ith pass dij is

$$
d_{i j}=d_{i, \text { min }}+\left(d_{i, \text { max }}-d_{i, \text { min }}\right) /\left(j / m_{i}\right) \quad \mathrm{j}=0,1,2, \ldots, \mathrm{m}_{\mathrm{i}}
$$

where mi for $\mathrm{i}=0,1,2, \ldots \mathrm{n}$ is a suitable integer, the value of mi is selected considering $\mathrm{d}_{\mathrm{i}, \max }$ and $\mathrm{d}_{\mathrm{i}, \min }$ and the compromise between the requirements of optimization and computer time. It may be noted that the numerical value of quotient $(q / p-1)$ in equation (3) is negative. Therefore, minimization of cost for finish pass can be achieved by using the maximum permissible value of feed under the constraints. The following steps are used to find the cost for finish pass.

Step 1. The maximum feed value satisfying the following constraints is determined for a given depth of cut

$$
\begin{aligned}
& \frac{C_{o}^{1 / p}}{T_{p}^{1 / p} \cdot v_{\max }} \leq f_{S}^{q / p} \cdot d_{S}^{r / p} \leq \frac{C_{o}^{1 / p}}{T_{p}^{1 / p} \cdot v_{\min }} \\
& f_{\min } \leq f_{S} \leq \min \left(f_{\max },\left(8 R R_{\max }\right)^{1 / 2}\right) \\
& k_{1} f_{S}^{\mu} d_{S}^{v} \leq F_{\max } \\
& f_{S}^{(\mu-q / p)} \cdot d_{S}^{(v-r / p)} \leq \frac{6120 \eta T_{p}^{1 / p} p_{\max }}{k_{1} C_{o}^{1 / p}}
\end{aligned}
$$

The optimum value of feed $f_{s}^{*}$ is selected such that

$$
f_{S}^{*}=\min \left(f_{S}^{1}, f_{S}^{2}, f_{S}^{3}, f_{S}^{4}\right)
$$

Where

$$
\begin{aligned}
& f_{S}^{1}=\frac{C_{o}^{1 / q}}{T_{p}^{1 / q} \cdot v_{\min }^{p / q} \cdot d_{S}^{r / q}} \\
& f_{S}^{2}=\min \left(f_{\max },\left(8 R R_{\max }\right)^{1 / 2}\right) \\
& f_{S}^{3}=\left[\frac{F_{\max }}{k_{1}\left(d_{S}\right)^{v}}\right]^{1 / \mu} \\
& f_{S}^{4}=\left[\frac{6120 \eta \cdot T_{p}^{1 / p} \cdot P_{\max }}{k_{1} \cdot C_{o}^{1 / p} \cdot d_{S}^{(v-r / p)}}\right]^{1 /(\mu-q / p)}
\end{aligned}
$$


Step 2. For the $f_{s}^{*}$, Tp and dS the quantity $v_{s}^{*}$ is obtained using,

$$
v_{S}^{*}=\frac{C_{o}^{1 / p}}{T_{p}^{1 / p} \cdot f_{S}^{* q / p} \cdot d_{S}^{r / p}}
$$

Step 3. Next the minimum cost for the finish pass is obtained using the following relationship

$$
U_{C_{S}}^{*}=A_{1} \cdot f_{S}^{*(q / p-1)} \cdot d_{S}^{r / p}+A_{2}
$$

These steps are also applicable for finding minimum cost for rough pass, for each $\mathrm{dS}=\mathrm{doj}, \mathrm{j}=0,1,2, \ldots$ mi., minimum finish cost ${ }_{U_{c_{j}}^{*}}^{*}$ is determined using steps 1 to 3. These costs are tabulated along with optimum values for speed $v_{s j}^{*}$ and feed $f_{s j}^{*}$. Similar procedure is adopted for various $\operatorname{dri}=\operatorname{dij}, j=0,1,2, \ldots \mathrm{mi}, \mathrm{i}=1,2, \ldots \mathrm{n}$, and each rough pass $U_{c_{r i j}^{*}}^{*}, v_{c_{r i j}^{*}}^{*}$ and $f_{r_{i j}^{*}}^{*}$ are determined.

\section{Phase 2}

In this phase, an optimal combination of depths of cut $d_{S}^{o p t}$ and $d_{r i}^{o p t}, i=1,2, \ldots n$, optimum number of rough passes $\mathrm{n}^{\mathrm{opt}}$, and total minimum production cost $U^{\mathrm{opt}}$ are determined. Let $\mathrm{n}$ be the maximum number of rough passes required, the number of passes needed to remove the total depth of material will be $(\mathrm{n}+\mathrm{l})$; including the finish pass. The integer variables $X_{i j} ; i=0,1,2, \ldots n ; j=1,2, \ldots m$ are defined such that.

$\mathrm{i}=0$; implies finish pass.

$\mathrm{i}=1,2, \ldots \mathrm{n}$; implies ith rough pass.

$\mathrm{j}=1,2, \ldots \mathrm{m}_{\mathrm{i}}$; implies correspondence to $\mathrm{jth}$ depth of cut

$X_{i j}=1$ if $d_{j}$ value of depth of cut is selected in ith pass.

$X_{i j}=0$ if dj value of depth of cut is not selected in ith pass.

The minimization of total production cost $\mathrm{U}$ is given by the following model minimize

$$
\begin{aligned}
& U=U_{C_{s}}+\sum_{i=1}^{n} U_{C_{r i}}+A_{5} \\
& \sum_{i=0}^{n} \sum_{j=0}^{m i} C_{i j} X_{i j}+A_{5}
\end{aligned}
$$

where corresponding to a particular $\mathrm{d}_{\mathrm{ij}}, C_{i j}=U_{C_{s j}}^{*}$ for $\mathrm{i}=0$; and $C_{i j}=U_{C_{r j}}^{*}$ for $\mathrm{i}=1,2, \ldots \mathrm{n}$. The objective equation (8) is minimized subjected to the following constraints:

$$
\begin{aligned}
& \sum_{j=0}^{m o} X_{o j}=1 \\
& \sum_{j=0}^{m i} X_{i j}=1 \quad \text { for } i=1,2, \ldots n \\
& \sum_{j=0}^{m i} \sum_{i=0}^{n} d_{i j} X_{i j}=d_{t}
\end{aligned}
$$

Constraint (10) implies that there is only one $d_{o j}$ selection for the finish pass and the finish pass must always be selected. Constraint (11) implies that there is only 
one $\mathrm{d}_{\mathrm{ij}}$ selection in case a rough pass is selected. Constraint (12) implies that the sum of individual depths of cut is equal to total depth of cut. The following constraint implies that the individual rough depths of cut selected must be of the minimum range and not equal to zero.

$$
R_{a}=\min \left(d_{i j \max }-d_{i j \min }\right)
$$

Where $\mathrm{R}_{\mathrm{a}}$ : the range, $d_{i j m a x}$ : maximum depth of cut for rough passes and $d_{i j m i n}$ : minimum depth of cut for rough passes.

\section{Illustrative Example}

The multipass example given by Shin and Joo [4] and considered by Gupta et al [5], is considered here again for the purpose of examination and explanation for the proposed method. The following are the data of the problem:

\begin{tabular}{lll}
\hline $\mathrm{D}=50 \mathrm{~mm}$ & $\mathrm{~L}=300 \mathrm{~mm}$ & $\mathrm{D}_{\mathrm{t}}=6 \mathrm{~mm}$ \\
\hline $\mathrm{d}_{\min }=1.0 \mathrm{~mm}$ & $\mathrm{~d}_{\mathrm{i} \text { max }}=3.0 \mathrm{~mm}$ & $\mathrm{i}=0,1, \ldots \mathrm{n}$ \\
\hline $\mathrm{f}_{\min }=0.1 \mathrm{~mm} / \mathrm{rev}$ & $\mathrm{f}_{\max }=0.9 \mathrm{~mm} / \mathrm{rev}$ & $\mathrm{C}_{\mathrm{o}}=6 \times 10^{11}$ \\
\hline $\mathrm{V}_{\min }=5 \mathrm{~m} / \mathrm{min}$ & $\mathrm{V}_{\max }=500 \mathrm{~m} / \mathrm{min}$ & $\mathrm{p}=5$ \\
\hline $\mathrm{T}_{\min }=25 \mathrm{~min}$ & $\mathrm{~T}_{\max }=45 \mathrm{~min}$ & $\mathrm{q}=1.75$ \\
\hline $\mathrm{F}_{\max }=200 \mathrm{~kg}_{\mathrm{f}}$ & $\mathrm{P}_{\max }=5 \mathrm{~kW}$ & $\mathrm{k}_{1}=108$ \\
\hline $\mathrm{R}_{\mathrm{r}}=0.1 \mathrm{~mm}$ & $\mathrm{R}_{\max }=0.01 \mathrm{~mm}$ & $\mu=0.75$ \\
\hline $\mathrm{R}=1.2 \mathrm{~mm}$ & $v=0.95$ & $\xi=1$ \\
\hline $\mathrm{h}_{1}=7 \times 10^{-4}$ & $\mathrm{~h}_{2}=0.3$ & $\mathrm{k}_{\mathrm{o}}=0.5 \$ / \mathrm{min}$ \\
\hline $\mathrm{k}_{\mathrm{t}}=2.5 \$ /$ cutting edge & $\mathrm{k}_{\mathrm{p}}=0.75 \mathrm{~min} /$ piece & $\mathrm{t}_{\mathrm{e}}=1.5 \mathrm{~min} /$ cutting edge \\
\hline $\mathrm{r}=4.75$ & & \\
\hline
\end{tabular}

For the given data $A_{5}, A_{1}$ and $A_{2}$ are calculated by using equations (2), (4) and (5) respectively. The calculated values were $A_{5}=0.375, A_{1}=0.249 ;\left(\operatorname{assuming} T_{p}=\right.$ 25min) and $A_{2}=0.255$

For $\mathrm{d}_{\mathrm{t}}$ up to $10.0 \mathrm{~mm}$, the maximum number of rough passes are assumed to be 3. The values of $m_{i}$ for $i=1,2, \ldots n$ is taken as 20 for generation of depth of cut series. Therefore,

$$
\begin{aligned}
& \mathrm{d}_{\mathrm{i} 0}=1.0 \mathrm{~mm} \\
& \mathrm{~d}_{\mathrm{i} 1}=1+(3.0-1.0)(1 / 20)=1.1 \mathrm{~mm} \\
& \mathrm{~d}_{\mathrm{i} 2}=1.2 ; \mathrm{d}_{\mathrm{i} 3}=1.3 \text { and so on up to } \mathrm{d}_{\mathrm{i} 20}=3.0 \mathrm{~mm}
\end{aligned}
$$

The minimization of the total cost $\mathrm{U}$ may be stated as

$$
\min \mathrm{U}=\mathrm{U}_{\mathrm{C}_{\mathrm{S}}}+\sum_{i=1}^{n} U_{C_{r i}}+A_{5}
$$

\section{Phase I}

In this phase the cost for finish pass and rough pass are minimized separately for various depths of cut. The cost minimization problem for finish pass may be stated as

$$
\min \mathrm{U}_{\mathrm{C}_{\mathrm{S}}}=0.255+0.249 f_{S}^{-0.65} \cdot d_{S}^{0.15}
$$

Subjected to 


$$
\begin{aligned}
& 0.238 \leq f_{S}^{0.35} \cdot d_{S}^{0.15} \leq 23.8 \\
& 0.10 \leq f_{S} \leq \min (0.90,0.31)=0.31 \\
& f_{S}^{0.75} \cdot d_{S}^{0.95} \leq 1.852 \\
& f_{S}^{4} \cdot d_{S}^{0.8} \leq 2.020 \\
& 1.0 \leq d_{S} \leq 3.0
\end{aligned}
$$

A computer program was developed for this case, and the values of were calculated using steps 1 to 3 for various depths of cut $d_{s}=d_{o j}, j=0,1, m_{0}$. These values are entered in the Table 1 .

Table 1 Optimal Cutting Parameters and Costs when the Total Stock is Removed in a Single Finish Pass

\begin{tabular}{ccccc}
\hline $\begin{array}{c}\text { Sample } \\
N \mathrm{o} .\end{array}$ & $\begin{array}{c}\mathrm{d}_{\mathrm{ij}} \\
(\mathrm{mm})\end{array}$ & $\begin{array}{c}v_{S i j}^{*} \\
(\mathrm{~m} / \mathrm{min})\end{array}$ & $\begin{array}{c}f_{S i j}^{*} \\
(\mathrm{~mm} / \mathrm{rev})\end{array}$ & $\begin{array}{c}U_{C_{S i j}}^{*} \\
(\$ / \text { piece })\end{array}$ \\
\hline 0 & 1 & 179.5 & 0.31 & 0.788 \\
\hline 1 & 1.1 & 177.0 & 0.31 & 0.766 \\
\hline 2 & 1.2 & 174.7 & 0.31 & 0.803 \\
\hline 3 & 1.3 & 172.6 & 0.31 & 0.809 \\
\hline 4 & 1.4 & 170.7 & 0.31 & 0.816 \\
\hline 5 & 1.5 & 168.9 & 0.31 & 0.822 \\
\hline 6 & 1.6 & 167.3 & 0.31 & 0.827 \\
\hline 7 & 1.7 & 165.8 & 0.31 & 0.832 \\
\hline 8 & 1.8 & 164.4 & 0.31 & 0.837 \\
\hline 9 & 1.9 & 163.0 & 0.31 & 0.842 \\
\hline 10 & 2 & 161.8 & 0.31 & 0.847 \\
\hline 11 & 2.1 & 160.6 & 0.31 & 0.851 \\
\hline 12 & 2.2 & 159.5 & 0.31 & 0.855 \\
\hline 13 & 2.3 & 158.4 & 0.31 & 0.859 \\
\hline 14 & 2.4 & 157.4 & 0.31 & 0.863 \\
\hline 15 & 2.5 & 156.4 & 0.31 & 0.867 \\
\hline 16 & 2.6 & 155.5 & 0.31 & 0.870 \\
\hline 17 & 2.7 & 154.7 & 0.31 & 0.874 \\
\hline 18 & 2.8 & 153.8 & 0.31 & 0.877 \\
\hline 19 & 2.9 & 153.0 & 0.31 & 0.880 \\
\hline 20 & 3 & 152.2 & 0.31 & 0.884 \\
\hline
\end{tabular}

The cost minimization problem for the rough pass is stated as; $U_{C_{S}}=0.255+0.249 f_{r}^{-0.85} \cdot d_{r}^{0.15}$

Subject to

$$
\begin{aligned}
& 0.238 \leq f_{r}^{0.35} \cdot d_{r}^{0.15} \leq 23.8 \\
& 0.10 \leq f_{r} \leq \min (0.90,0.979)=0.9 \\
& f_{r}^{0.75} \cdot d_{r}^{0.95} \leq 1.852 \\
& f_{r}^{4} \cdot f_{r}^{0.8} \leq 2.2020 \\
& 1.0 \leq d_{r} \leq 3.0
\end{aligned}
$$


The values of $f_{r i j}^{*}, U_{C r i j}^{*}, v_{r i j}^{*}$ are determined for $\mathrm{d}_{\mathrm{r}}=\mathrm{d}_{\mathrm{ij}}, \mathrm{j}=0,1, \ldots \mathrm{m}$. These values are entered in the following Table 2. It can be noted that these values are the same for all rough passes $(i=1,2, \ldots n)$.

Table 2 Optimal Cutting Parameters and Costs when the Total Stock is Removed in a Single Rough Pass

\begin{tabular}{|c|c|c|c|c|}
\hline $\begin{array}{c}\text { Sample } \\
\text { No. }\end{array}$ & $\begin{array}{c}\mathrm{d}_{\mathrm{ij}} \\
(\mathrm{mm})\end{array}$ & $\begin{array}{c}v_{r i j}^{*} \\
(\mathrm{~m} / \mathrm{min})\end{array}$ & $\begin{array}{c}f_{r i j}^{*} \\
(\mathrm{~mm} / \mathrm{rev})\end{array}$ & $\begin{array}{c}U_{r_{i j}}^{*} \\
\text { (\$/piece) }\end{array}$ \\
\hline 0 & 1 & 123.6 & 0.900 & 0.522 \\
\hline 1 & 1.1 & 121.9 & 0.900 & 0.525 \\
\hline 2 & 1.2 & 120.3 & 0.900 & 0.5290 \\
\hline 3 & 1.3 & 118.8 & 0.900 & 0.532 \\
\hline 4 & 1.4 & 117.5 & 0.900 & 0.535 \\
\hline 5 & 1.5 & 116.3 & 0.900 & 0.538 \\
\hline 6 & 1.6 & 115.2 & 0.900 & 0.541 \\
\hline 7 & 1.7 & 114.2 & 0.900 & 0.544 \\
\hline 8 & 1.8 & 113.2 & 0.900 & 0.546 \\
\hline 9 & 1.9 & 112.3 & 0.900 & 0.549 \\
\hline 10 & 2 & 111.4 & 0.900 & 0.551 \\
\hline 11 & 2.1 & 111.1 & 0.889 & 0.556 \\
\hline 12 & 2.2 & 112.6 & 0.838 & 0.569 \\
\hline 13 & 2.3 & 114.1 & 0.799 & 0.583 \\
\hline 14 & 2.4 & 115.5 & 0.750 & 0.597 \\
\hline 15 & 2.5 & 116.9 & 0.712 & 0.611 \\
\hline 16 & 2.6 & 118.3 & 0.678 & 0.625 \\
\hline 17 & 2.7 & 119.6 & 0.646 & 0.639 \\
\hline 18 & 2.8 & 120.9 & 0.617 & 0.653 \\
\hline 19 & 2.9 & 122.1 & 0.590 & 0.666 \\
\hline 20 & 3 & 123.3 & 0.566 & 0.680 \\
\hline
\end{tabular}

\section{Phase 2}

The same applied problem given in the beginning was analyzed. The results obtained are given in Table 3. These results have also been obtained using the method developed by Shin Joo [4], Gupta et al. [5], Saravanan et al. [11] and Satishkumar et al. [12]. All are listed in the same table.

Figure 1 shows the visual comparison among the cost obtained from each method. For $d_{t}=8 \mathrm{~mm}$ the proposed method results in 3 rough passes, two of $2.3 \mathrm{~mm}$ and one of $2.2 \mathrm{~mm}$ with range of $0.1 \mathrm{~mm}$ and a finish pass of $1.2 \mathrm{~mm}$. This gives a cost of $2.913 \$$ piece which is less than those obtained by Gupta's et al Shin et al methods and Simulated Annealing Method in the paper of Satishkumar et al, namely 2.946\$, $2.94 \$$ and $2.915 \$$ respectively. 
Table 3. Comparison of Results for Proposed Model with Gupta et al, Shin and Joo and other Nontraditional Methods

\begin{tabular}{|c|c|c|c|c|c|c|c|c|}
\hline & $\begin{array}{c}\text { Sample } \\
\text { No. }\end{array}$ & $\begin{array}{c}d_{t} \\
\mathrm{~mm}\end{array}$ & $\underset{\mathrm{mm}}{d_{S}^{o p t}}$ & $\underset{r 1}{d_{r m}^{o p t}}$ & $\begin{array}{c}d_{r 2}^{o p t} \\
\mathrm{~mm}\end{array}$ & $\begin{array}{c}d_{r 3}^{o p t} \\
\mathrm{~mm}\end{array}$ & $n^{o p t}$ & $\begin{array}{c}U^{o p t} \\
\$\end{array}$ \\
\hline \multirow{6}{*}{ 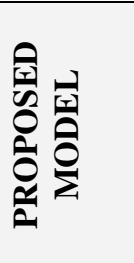 } & 1 & 6.0 & 1.2 & 2.3 & 2.5 & - & 2 & 2.372 \\
\hline & 2 & 8.0 & 1.2 & 2.3 & 2.3 & 2.2 & 3 & 2.913 \\
\hline & 3 & 8.5 & 1.2 & 2.4 & 2.4 & 2.5 & 3 & 2.983 \\
\hline & 4 & 9.0 & 1.2 & 2.5 & 2.6 & 2.7 & 3 & 3.053 \\
\hline & 5 & 9.5 & 1.2 & 2.7 & 2.8 & 2.8 & 3 & 3.123 \\
\hline & 6 & 10.0 & 1.2 & 2.9 & 2.9 & 3.0 & 3 & 3.193 \\
\hline \multirow{6}{*}{ 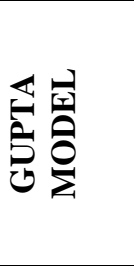 } & 1 & 6.0 & 1.2 & 2.7 & 2.1 & - & 2 & 2.371 \\
\hline & 2 & 8.0 & 1.0 & 2.0 & 3.0 & 2.0 & 3 & 2.946 \\
\hline & 3 & 8.5 & 1.0 & 3.0 & 2.0 & 2.5 & 3 & 3.006 \\
\hline & 4 & 9.0 & 1.0 & 3.0 & 3.0 & 2.0 & 3 & 3.076 \\
\hline & 5 & 9.5 & 1.2 & 3.0 & 3.0 & 2.3 & 3 & 3.123 \\
\hline & 6 & 10.0 & 1.2 & 3.0 & 3.0 & 2.8 & 3 & 3.193 \\
\hline \multirow{6}{*}{ 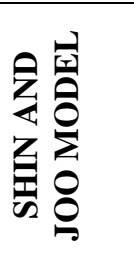 } & 1 & 6.0 & 0.4 & 2.8 & - & - & 2 & 2.401 \\
\hline & 2 & 8.0 & 0.4 & 2.53 & - & - & 3 & 2.94 \\
\hline & 3 & 8.5 & 0.4 & 2.7 & - & - & 3 & 3.012 \\
\hline & 4 & 9.0 & 0.4 & 2.87 & - & - & 3 & 3.081 \\
\hline & 5 & 9.5 & 0.4 & 2.275 & - & - & 4 & 3.415 \\
\hline & 6 & 10.0 & 0.4 & 2.4 & - & - & 4 & 3.483 \\
\hline \multirow{6}{*}{ 氞 } & 1 & 6.0 & 1.20 & 2.11 & 2.69 & & 2 & 2.371 \\
\hline & 2 & 8.0 & 1.18 & 2.29 & 2.10 & 2.43 & 3 & 2.913 \\
\hline & 3 & 8.5 & 1.18 & 2.29 & 2.09 & 2.93 & 3 & 2.982 \\
\hline & 4 & 9.0 & 1.20 & 2.82 & 2.09 & 2.89 & 3 & 3.051 \\
\hline & 5 & 9.5 & 1.19 & 2.76 & 2.79 & 2.76 & 3 & 3.122 \\
\hline & 6 & 10.0 & 1.19 & 3.0 & 3.0 & 2.81 & 3 & 3.190 \\
\hline \multirow{6}{*}{ 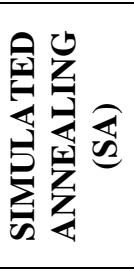 } & 1 & 6.0 & 1.20 & 2.63 & 2.17 & & 2 & 2.372 \\
\hline & 2 & 8.0 & 1.19 & 2.25 & 2.23 & 2.33 & 3 & 2.915 \\
\hline & 3 & 8.5 & 1.15 & 2.63 & 2.48 & 2.24 & 3 & 2.986 \\
\hline & 4 & 9.0 & 1.19 & 2.87 & 2.65 & 2.29 & 3 & 3.053 \\
\hline & 5 & 9.5 & 1.18 & 2.82 & 2.71 & 2.79 & 3 & 3.123 \\
\hline & 6 & 10.0 & 1.20 & 2.96 & 2.98 & 2.87 & 3 & 3.192 \\
\hline \multirow{6}{*}{ 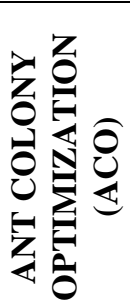 } & 1 & 6.0 & 1.195 & 2.285 & 2.250 & & 2 & 2.371 \\
\hline & 2 & 8.0 & 1.190 & 2.110 & 2.095 & 2.600 & 3 & 2.911 \\
\hline & 3 & 8.5 & 1.195 & 2.805 & 2.340 & 2.160 & 3 & 2.981 \\
\hline & 4 & 9.0 & 1.200 & 2.290 & 2.780 & 2.730 & 3 & 3.050 \\
\hline & 5 & 9.5 & 1.195 & 2.470 & 2.940 & 2.895 & 3 & 3.119 \\
\hline & 6 & 10.0 & 1.195 & 3.000 & 3.000 & 2.805 & 3 & 3.185 \\
\hline
\end{tabular}

However this cost is equal to the cost obtained by Genetic Algorithm but more than the cost obtained by Ant Colony Optimization in Satishkumar et al paper [12] where the cost is $2.911 \$$. Further, the proposed method yields significantly less cost for 
$\mathrm{d}_{\mathrm{t}}=8.5 \mathrm{~mm}$ and $9.0 \mathrm{~mm}$ comparing with Gupta's et al Shin et al methods. This is because combination of rough passes with minimum range and a finish pass on the higher side of the recommended range of finish pass have a higher feed rate than other combinations suggested by the other methods mentioned earlier. The proposed method gives lower cost when it is possible to reduce the range among rough passes and use a finish pass on the higher side of the recommended finish pass range. Also, this leads to reduce number of passes.

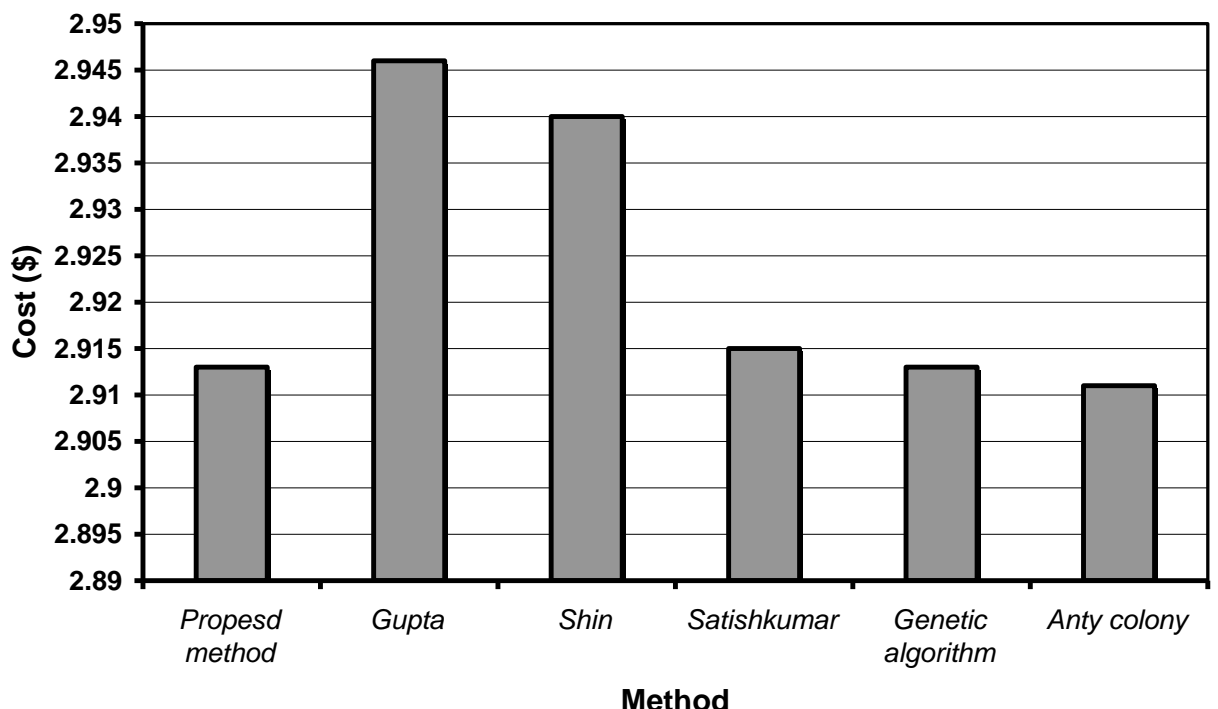

Fig.1. The cost obtained from each analysis method

\section{DISCUSSION AND CONCLUSION}

In this paper, the optimal subdivision of total depth of cut during cost optimization method in multipass turning with constraints was investigated. The proposed model was based on the total production cost minimization by summation of the minimum costs of individual rough passes and the finish pass. The cost of each rough pass or finish pass was independently minimized and then the optimal subdivision of total depth of cut was obtained. It has been used the strategy of selecting a combination of rough passes with minimum range and a finish pass on the higher side of the recommended finish pass range. This yields a lower minimum cost than that obtained by commonly practiced strategy of having minimum depth of cut in the finish pass and removing the remaining depth of cut in number of rough passes of equal size developed earlier by other researchers.

The results of the illustrative examples and its variation show that the proposed methodology should be advocated for the selection of depths of cut for rough passes and finish pass in contained multipass turning operation. For various depths of cut ranging from $6 \mathrm{~mm}$ to $10 \mathrm{~mm}$, minimum production costs, which are lower than or equal to the ones found using other published methods were obtained. 


\section{REFERENCES}

1. IWATA, K., MUROSTY, Y., and OBA, F., "Optimization of cutting conditions for multipass operation considering probabilistic nature in machining process". Journal of Engineering for Industry, Transaction of the ASME, 99, 1977, pp 210 - 217.

2. LAMBERT, B. and WALVEKR, A., " Optimization of multipass machining operation". INT. J. PROD. RES., 16, 1978, pp 259-265.

3. YELLOWLEY, I., and GUNN, E. A., "The optimal subdivision of cut in multipass machining operations" INT. J. PROD. RES., V. 27, No.9, 1989, pp 15731588.

4. SHIN, Y. C., and JOO, Y. S., "Optimization of machining conditions with practical constraints". INT. J. PROD. RES., V. 30, No. 12, 1992, pp 2907-2919.

5. GUPTA, R., BATRA, J. L., and LAL G. K., " Determination of optimal subdivision of depth of cut in multipass turning with constraints" INT. J. PROD. RES., V. 33, No. 9, 1995, pp 2555-2565.

6. SARAVANAN $\mathrm{R}$ et al. "Comparative analysis of conventional and nonconventional optimization techniques for CNC turning process". Int. J Adv Manuf Tech., 2001, 17:471-476

7. SARAVANAN R. et al. "Machining parameters optimization for turning cylindrical stock into a continuous finished profile using genetic algorithm (GA) and simulated annealing (SA)". Int. J. Adv Manuf. Tech., 2003, 21:1-9.

8. VIJAYAKUMAR K. et al. "Optimization of multi-pass turning operations using ant colony system". Int J Mach Tools Manuf., 2003, 43:1633-1639.

9. CHEN, M. C., TSAI, D. M., "A simulated annealing approach for optimization of multi-pass turning operations". Int. J Prod. Res.,1996, 34:2803-2825

10. FRANCI, C., BALIC J., "Optimization of cutting process by GA approach" Robot Comput Integr. Manuf. 2003, 19:113-121

11. SARAVANAN, R. et al. "A multi objective genetic algorithm (GA) approach for optimization of surface grinding operations". Int. J. Mach. Tools Manuf. 2002, 42:1327-1334.

12. SATISHKUMAR et al. "Optimization of depth of cut in multi-pass turning using non-traditional optimization techniques". Int. J. Adv. Manuf. Tech. 2006, 29: 230238. 


\section{نموذج مقترح لتحقيق الطريقة المثلى لعملية الخراطة المقيدة والمتعددة الأثواط}

توجد العديد من الطرق التي تهدف إلى تحديد أفضل توزيع لانجاز عمق القطع الكلي أثتاء عملية

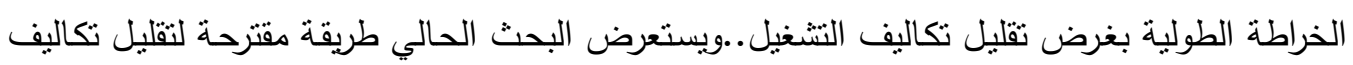
النتشيل مقارنـة بطرق سـابقة نم تطبيقها لنفس الغرض. وقد تم تطبيق الطريقة المقترحة على عملية

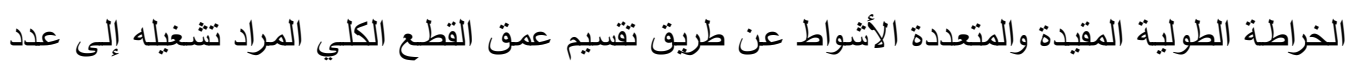

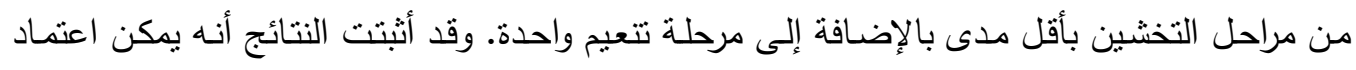

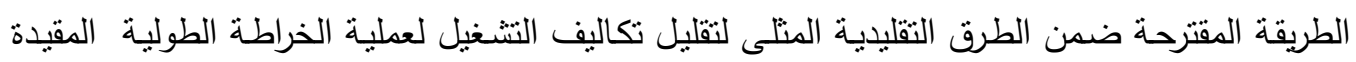
والمتعددة الأشواط . 